\title{
Deep venous thrombosis: a continuing problem
}

\author{
John H Scurr, P D Coleridge-Smith, \\ James H Hasty
}

Department of Surgical Studies, University College and Middlesex Hospital Medical School, London John H Scurr, FRCS, senior lecturer and consultant surgeon P D Coleridge-Smith, FRCS, senior lecturer

James H Hasty, PHD, senior scientist

Correspondence to: $\mathrm{Mr} \mathrm{J} \mathrm{H}$ Scurr, Department of Surgical Studies, Middlesex Hospital, London WIN 8AA
The incidence of deep vein thrombosis after major operations in patients over the age of 40 approaches $30 \%$ if no prophylactic measures are used.' Many patients discharged from hospital are still at risk at home and the question arises whether prophylaxis should be continued after patients have been discharged. To try to answer this question we followed up patients, most of whom received prophylaxis for deep vein thrombosis during their stay in hospital, for up to six weeks after their discharge from hospital.

\section{Patients, methods, and results}

Patients over the age of 40 having major operations were studied. All patients gave informed consent, and only those who were suitable for scanning of the uptake of fibrinogen labelled with iodine-125 were included. Patients were entered into the study two days before discharge from hospital. Before entry all patients had a full non-invasive venous assessment including scanning of the uptake of fibrinogen labelled with iodine-125, ${ }^{2}$ Doppler ultrasonography, ${ }^{3}$ strain gauge plethysmography to measure maximum venous outflow, ${ }^{+}$and, if indicated, contrast venography to exclude pre-existing deep vein thrombosis.

Of the 57 patients studied, 28 were men and 29 women. The mean age was $62 \cdot 7$ (SD 12.7) years. During their stay in hospital 52 patients received prophylaxis for deep vein thrombosis in the form of wearing graduated elastic compression stockings, taking low doses of heparin, having intermittent pneumatic impression, or both taking low doses of heparin and wearing graduated compression stockings. Five patients received no prophylaxis. All patients were encouraged to walk soon after operation.

Deep vein thrombosis was diagnosed and treated in six patients before discharge; four of them had not received prophylaxis. Prophylaxis was discontinued in the remaining 50 patients who had no signs of deep vein thrombosis when discharged.

Patients were visited in their homes on alternate days and studied by Doppler ultrasonography and scanning of radioactively labelled fibrinogen. A further injection of radioactive fibrinogen was given when the total count over the heart dropped below 50 counts per second. In giving up to three injections of radiolabelled fibrinogen we were able to study the patients for up to three or four weeks after discharge. During the sixth week after discharge all patients had non-invasive venous assessment and venography was done to confirm deep vein thrombosis. Thirteen of the 51 patients who had not developed deep vein thrombosis at discharge did so during the six weeks of follow up, one during the first three days, seven between four and six days, three between seven and 10 days, and two after more than 10 days.

\section{Comment}

Our results show that the risk of developing thromboembolic disease can extend beyond a stay in hospital. Many of the risk factors in hospital for developing deep vein thrombosis persist after discharge. On leaving hospital, many patients remain immobile and, indeed, may be less mobile at home than they were in hospital.

Our results suggest that the incidence of venous thrombosis in patients after discharge may be considerably greater than was originally thought. Continuing with prophylaxis for longer may be necessary to reduce this risk still further. Patients developing deep vein thrombosis in hospital, where it can be diagnosed and treated, may fare better than those who develop deep vein thrombosis at home, where it may not be diagnosed as easily.

1 National Institutes of Health. Consensus development conference on the prevention of venous thrombosis and pulmonary embolism. JAMA 1986; 256:744-9.

2 Negus D, Pinto DJ, LeQuesne LP, Brown N, Chapman M. 125-I-labelled fibrinogen in the diagnosis of deep vein thrombosis and its correlation with phlebography, Br J Surg 1968:55:835-9.

3 Sigel B, Felix WR Jr, Popky GL, Ipsen J. Diagnosis of lower limb venous thrombosis by Doppler ultrasound technique. Arch Surg 1972;104:174-9.

4 Barnes RW, Collicott PE, Mozersky DJ, Summer DS, Strandness DE. Noninvasive quantitation of maximum venous outflow in acute thrombophlebitis. Surgery 1972;72:971.9.

Accepted 28 March 1988

\section{Delayed communication between hospitals and general practitioners: where does the problem lie?}

\section{T M Penney}

Sundon Medical Centre, Luton, Bedfordshire

T M Penney, DRCOG, trainee general practitioner

Correspondence to 47 Bedford Road, Barton le Clay, Bedfordshire MK45 4LL.
The poor standard of communications between hospitals and general practitioners after patients have been discharged has long been noted ${ }^{1-3}$ I sought the reasons behind the general practitioners' delay in receiving such communications.

\section{Patients, methods, and results}

All acute admissions to a district general hospital from this four partner practice of 7600 patients were monitored between November 1986 and May 1987. A record of each admission was compiled consisting of the name of the patient, address, probable diagnosis, specialty concerned, date of admission, and date of receipt of both discharge letter and summary. A total of 104 patients were admitted, of whom seven died in hospital. The average length of stay was $7 \cdot 4$ days.

Discharge letters were given to the patient for delivery by hand to their general practitioner. Eighteen such letters were never received. The average delay for receipt of the other 86 was $4 \cdot 3$ days, with $34(40 \%)$ being received within two days and $75(88 \%)$ within one week (table). The consultant's name was stated in $84(98 \%)$ letters, the hospital's name in $83(96 \%)$, the diagnosis in $84(98 \%)$, and the arrangements for follow up in $53(62 \%)$.

Discharge summaries were posted to the general practitioner; only one communication was by telephone, about the death of a patient. Twenty six (25\%) discharge summaries were never received. For the 78 that arrived the average delay was $25 \cdot 3$ days. Most of this time was taken by typing $(20.8$ days) rather than by delays in the post. The longest delay was 114 days. Nine $(12 \%)$ summaries arrived within one week and 30 (39\%) within two weeks after discharge (table).

A spot check carried out shortly after the end of the study showed that 1080 discharge summaries were waiting to be typed in the hospital. This represents $5 \%$ 